\title{
Time, tense and other matters
}

\author{
HANS ARNDT \\ Institut for Lingvistik, Aarhus Universitet, Danmark
}

Dieser Beitrag erforscht die Beziehungen zwischen Tempus, Aspekt und Modalität in einer engen Auswahl von Sprachen und verficht die These, dass hier keine einfache Beziehung zwischen Ausdruck und Inhalt vorliegt. Aspekt, zum Beispiel, ist eng mit der Kategorie Tempus/Zeit verbunden; und: obwohl der unmarkierte Inhalt des (indoeuropäischen) Tempus die temporale Abfolge ist, ist Sequentialität nicht die einzige Konzeptualisierung von Zeit.

\section{INTRODUCTION}

When something is explained, it is by necessity reduced and simplified in the process. This holds for a cow, which may be reduced from a wonderfully calm, ruminating, warm, large, inscrutable animal to a milk production unit. It holds even more for language. The important thing for the explainer is to be aware how much he is reducing, and what he is leaving out. He may want to come back and explain that next time round.

My aim with this paper is not to introduce novel and startling facts, but to correlate various expressions and their meanings, in order to try to explain time in language. I shall take my point of departure in morphological tense, including auxiliaries as I go along. I shall leave out lexical time expressions (like day, long, continually, once, while, lately, etc. etc. - and of course the word time itself), even though these would of course also be relevant in a full exposition of time in language.

Tense is a formal system in some languages, and its relation to the concept of time is somewhat tortuous; and I cannot, of course, discuss a particular time content, without indicating the types of expressions that carry it. Tense is the time-honoured (!) expression of time. But once we get started, it will lead us along other paths as well.

A second proviso follows logically from the phrase that slipped into the previous paragraph: "in some languages". There are languages that do not show any system remotely similar to the tenses found in European languages (and indeed in other places as well). Hence we cannot start by trying to be universal about it, not even by being logical about it, because we cannot know how much our logic is influenced by the language(s) we know. This does not mean that it is impossible to look for the logic behind language. Only that the logic, or conceptualisation, of time is not universal.

Moreover, if we do want to explore time content as well as time expression (which of 
Arndt, Time, tense ...

course we do), we have to know the languages for which we do it, well enough to be able to detect subtle shades of meaning (in my case that includes English and Danish; examples from other languages are tentative). In other words we are forced to start with very few languages, and to content ourselves with one type (or a few types) of linguistic time sign system - whose validity for other languages is for others to verify/falsify.

\section{TENSE AND AUXILIARIES}

Initially it is important to make explicit what we understand by tense. In the narrowest conception it is one morphological paradigm, consisting in English, German and Danish of only two terms, in French presumably of three, and in Latin of six. (The Latin tense system, with its present, past and future, and the corresponding three 'pre-tenses' - if that is what they are - seems to exert a strong influence on modern ideas of tense. I shall come back to that.)

However, it soon turns out that tense (in this narrow sense) is closely bound up with other paradigms - which are close in placement, and seem to be close in meaning also, as will become evident in the content analysis. So in order to make the initial analysis broad enough to make it worthwhile, it should reasonably include auxiliaries as well as verbal inflection.

Chomsky (already in 1957: 111) set out the following elegant formulation of verbal inflection and auxiliaries in English:

1) Tense (+modal) (+have) $(+b e)$

He reserved the passive for transformational purposes, but if we add that, we get the following example of a maximal verbal expression:

2) At a time when the fields should have been being sown with corn, they were under water

Altogether there are five paradigms, four of which have two terms each (the exception being 'modal', which has five or seven). It is tempting to formulate the maximal syntagm thus:

3) \pm preterite, \pm modal, \pm perfective, \pm progressive, \pm passive

The unmarked (minimal) expression is the simple present, the maximal expression is the one illustrated in (2).

The reason why I have left the modal paradigm as if it were a two-term one, is that the effects of the modal auxiliaries on tense/time are similar - though by no means identical. This is not an issue I shall go into, but it may be pertinent to point out that modality is closely related to speech act content, hence the 'time' of a modal auxiliary is often different from the time reference of the predication proper.

The English system is fairly simple, because there is no recursion in it: there is no way you can have a modal after a perfective expression, or indeed any other order than the one given in (1). (Not, at least, if we accept the simplicity built into the presentation 
of the system - any decent beginner's grammar for Danish learners of English will inform you that har kunnet is translated as has been able to. Anyway this kind of expression is usually excluded from modality proper, the use of a 'modal' verb in Danish notwithstanding.)

\section{MoRPHOlOGiCAL TENSE SYSTEMS AND MODALS}

Given that the passive is likely to have little to do with time, I shall content myself with examining the other four. But let me start at the beginning: the first paradigm in the syntagm. In English the present vs preterite tenses:

\section{4a) When I was younger, I wanted to change the world \\ 4b) Now I don't care}

Clearly (4) shows a difference between what held before and what holds now. In other words the referential time content of the preterite (4a) is sequentiality: past time relative to the moment of speaking, whereas the referential time content of the present is nonsequential, or simultaneous with the moment of speaking.

The simple way to put this, is to say that the present/preterite tenses refer to 'now/then', that the time reference is deictically based, and that it has to do with time sequence. However, other examples show that there is a broader deictic reference, of which time 'now/then' is only one manifestation:

5a) Sorry to disturb you - I just wanted to ask you a question

5b) If I had the time, I would wait for you, but I don't

In $(5 a, b)$ the preterite tense is used about time-now, with subtly different meanings: either to lessen the obligation (5a, cp. I want to ask you a question), or to indicate irreality (5b). In Danish the irreal preterite is even used without a modal auxiliary in main clauses (much rarer, perhaps non-existent, in English):

6) Hvis jeg havde en million, gav jeg den ikke til Dig! ('If I h a d a million, I wouldn't give it to you!')

Conversely, both English and Danish may use the present tense about a vividly remembered or presented past time (the 'historic present'). Furthermore the present tense is often used to refer to the future, more so in Danish than in English, but sufficiently often in both languages for me to suggest the following generalization:

The simple present-preterite distinction in Danish and in English indicates a difference in 'actuality' ('this' vs. 'that'), of which 'now' vs. 'then' is only one particular instance.

References to future time are generally seen to belong to 'now', the 'logic' being, presumably, that predictions or decisions about the future are made at the moment of speaking. 
Arndt, Time, tense ...

There is nothing universally logical about this - another 'logic' might dictate a basic distinction between on the one hand the past/present - so to speak what we 'have' - and on the other the future - what we 'have' not yet, but can only plan for. For instance, this seems to be the case in the Amazonian language Urubu-Kaapor, which makes no present/past distinction but has a special particle ( $t a)$ to indicate the future (Kakumasu 1986). Similarly, Inuit and Aleut languages have a rich modal morphology, but little in the way of tense (e.g. Bergsland 1997). I shall not go into this, but it is interesting that similar systems have developed in areas so far apart.

As for Danish and English references to future time, it seems that the present tense is used when the future is so uncontroversial as to be virtually part of the present time, whereas a modal is included when there is a need to express or stress either the predictive or the obligational nature of the proposition:

7) Når vi ko mmer til London, får vi en chance for at stroekke benene ('When we get to London, we have a chance to stretch our legs')

8) Hvis Du kommer på hospitalet, kommer jeg og besøger Dig ('If you go to hospital, I'll come and see you')

As appears from the examples, the need to express prediction or obligation is not felt in the same way in English and Danish. The reason why that is so, may be that English regularly uses another form (the so-called present progressive) to refer to the future, which may take care of most of the cases where future reference is uncontroversially present and planned and therefore a reference to 'this' world, as in:

9a) We are dining at six. If you a re not here, we sh all start without you

9b) Vi spiser klokken seks. Hvis Du ikke er her, starter vi uden Dig

Note that when we come to the less-than-obvious future, English uses shall start, whereas Danish uses the simple present. Interestingly, when Danish modalizes the future, the modal content often becomes more prominent than in the corresponding English expression:

10a) Jeg skal nok komme og besøge Dig (reassurance, with both a modal verb and the modal particle nok, 'Don't worry, I'll come and see you')

10b) Hvis Du ikke er her, må vi starte uden Dig (necessity, 'If you are not here, we shall have to start without you')

Anyway, we now have a basic distinction between 'this' (present tense) and 'that' (past tense), and when we want to express the future, this involves - to some extent - the modal paradigm (obligation or prediction). This system holds for English and Danish, though not along quite the same lines.

German has an auxiliary specifically for the future (werden), and French has a morphological future as a third term in the basic tense system. This means that in these two languages, the future has its own expression, and doesn't just ride on the present and the modals. At any rate the use of the present tense with future reference does not follow the same rules as in English or Danish. This suggests that there are two or three types of tense systems. (In fact, depending on the degree of delicacy, each language may be said to have a system of its own.) 


\section{The 'Perfective tenses'}

Latin seems to illustrate a very neat system, based on simple sequentiality. On the face of it, Latin seems to have three 'pre-tenses' on top of the three 'basic' tenses (all six morphological, at least in the active voice). But it is not as simple as that. The difference between the Latin alleged 'pre-present' perfectum and the 'basic' imperfectum is not a matter of time sequence, but of aspect. If Caesar had said "Venibam, videbam, vincebam" instead of the well known "Veni, vidi, vici", he would not have been placing his actions further back in time (in the past as opposed to the 'pre-present'), he would have been presenting them as ongoing. The other two 'pre-tenses' (the 'pre-past' plusquamperfectum and the 'pre-future' futurum exactum) are, as far as I know, sequential time indicators. But in the distinction between perfectum and imperfectum the time-tense relationship is not purely sequential, but mixed up with an aspectual perspective.

It may be significant that the first Latin grammarians used the terms imperfectum and perfectum to refer to the preterite and the perfective forms. The terms show that they were aware that the difference was one of ongoing vs finished, not simply sequential time. The futurum exactum on the other hand is clearly indicated as the 'pre-time' it is most often taken to be; but the term plusquamperfectum is surprising, since (if I understand it correctly) this normally does indicate a 'pre-past', not a 'more than perfect' aspect. There may be reasons for this terminology that I am unaware of.

Considering the terminological confusion, it may be helpful at this point to introduce different terms for expression and time content. At the same time I shall set up what I consider the unmarked relationship between the two:

\section{Expression \\ TENSE \\ - present tense \\ - preterite tense \\ - $\quad$ perfective tenses (in English with the auxiliary have)}

\section{ASPECT}

- perfect vs. imperfect aspect

- progressive vs non-progressive (terms used in English grammar for the be+-ing form)

MODAL AUXILIARIES

\section{Unmarked content}

Sequential time

- time of the point of utterance

- previous time, relative to the point of utterance

- previous time, relative to a contextual time; or retrospective perspective

Perspective on the duration of the lexical predicate

- finished vs. ongoing perspective

- finished vs. ongoing perspective

'Modality', i.e. non-factuality (closely related to past time/tense, but applicable to all sequential time indications) and/or desirability (closely related to the future time); or future time relative to the point of utterance

Note the terminological distinction between perfective tense and perfect aspect. 
Arndt, Time, tense ...

\section{The perfective in English and Danish}

Given the somewhat lopsided Latin tense-aspect system, what is the modern use of the perfective tenses? In fact expressions with the auxiliary have in English and Danish are remarkably similar to the Latin perfectum, plusquamperfectum and futurum exactum. If have is in the past tense (as in I had done it) or in the infinitive (as in I will have done it) they do indicate a 'pre-time', i.e. a time before some other point in time indicated in the context. But if have is in the present tense the situation is different:

11a) Jeg har vasket bilen. Jeg vaskede den i morges

11b) I have washed the car. I washed it this morning

The difference between have washed and washed is not a difference in referential time, but is more naturally seen as one of perspective - though clearly not the finished/ ongoing perspective of Latin, but a modern development: a matter of retrospection.

This use of the have-perfective may be related to the 'pre-time' use (though historical developments suggest that it need not be). Again, it is logical that the present perfective form is not used as a 'pre-present', since that is the same as the past.

The retrospective perspective has developed three variants in Danish: three different meanings of the same expression. The first is the resultative one illustrated in (11a) - jeg har vasket bilen implies the result that it is clean. The second may be termed continuative:

12a) Jeg har kaempet med min PC $i$ de sidste to timer

12b) I have been struggling with my PC for the last two hours

This does not imply any result, but 'durative continuity' - considering the capriciousness of PC programmes the situation may well continue. In English this kind of continuity is expressed by means of the present perfective progressive (12b), whereas a 'repetitive continuity' is expressed by means of the simple perfective (as in Danish):

13a) I have often had to fight to get the programme to do what I want 13b) Jeg har ofte voeret nødt til at slås for at fä programmet til at gøre som jeg vil

By repetitive continuity I mean that (13) implies that this has taken place repeatedly and is likely to happen again, in contrast to the past tense (I often had to fight / Jeg var ofte nødt til), which would probably imply that I had given up and got myself a Mac instead - so no continuity.

The third use of the have-perfective is, as far as I know, exclusively Danish: the modal or 'concluding' use:

14a) Voer ikke vred på ham for det. Det har voeret et uheld

14b) Don't be angry with him for that. It must have been an accident

As is evident from (14b), English here has to use a modal to express the epistemic implication: that this is my conclusion, not something I know. The English infinitive perfective (have been) is here used to indicate past time - with a modal the past tense is either impossible or ambiguous. 
Of the three the resultative use is probably the basic one. At any rate this has given rise in Danish to what may be termed a double perfective expression where the auxiliary have is repeated:

15a) Jeg har haft broekket benet

15b) I have had a broken leg

Note that broekket is not attributive, as is broken in English, but part of the verbal expression. The commonest implication of the double perfective is that the resultative reading is not valid in the way it would be for I have broken my leg. The difference between the double perfective and the preterite is that the former still implies some relevance of the event for the present: 'even though my leg is now healed, I know how it feels' (or whatever). In cases where the immediate result is not so obvious as with break, the different implications nevertheless hold:

16a) Jeg har haft ringet til ham

16b) I have tried to call him

Here the implication (as shown in the English translation) may be that I didn't get anything out of it - perhaps because he didn't answer or he wouldn't talk. It would be tempting to assume that the double perfective was placed before-in-time relative to the simple perfective, but (16) shows that this is not necessarily the case.

Also in English the resultative reading of the present perfective seems to be basic. The evidence is partly that the perfective is combined with the progressive form to express the durative continuity reading, and partly that a point-of-time adverbial does not go well with the English perfective (though it is fine in Danish):

17a) *I have washed the car yesterday

17b) Jeg har vasket bilen I går

However this has not led to the development of a double perfective in English. In a sentence like I have had the car washed the verb had is causative, not a perfective auxiliary.

In French the difference between le passé composé and l'imparfait is a matter of finished vs. ongoing perspective (as in Latin), but I believe it invites a 'pre-time' reading if combined with the past tense (as in j'avais parlé).

\section{TIME AND PERSPECTIVE}

I suggested earlier that perspective was often related to time. This is apparent if we try to depict the use of the finished versus ongoing perspective. It is most illustratively done on a time line. In figure 1 we have the finished perspective ('angle of vision'). The speaker is as it were 'above the fray', able to see the event as a whole. In figure 2 the speaker immerses himself in the event and disregards (or is unable to see) the beginning and end of it. 
Fig. 1

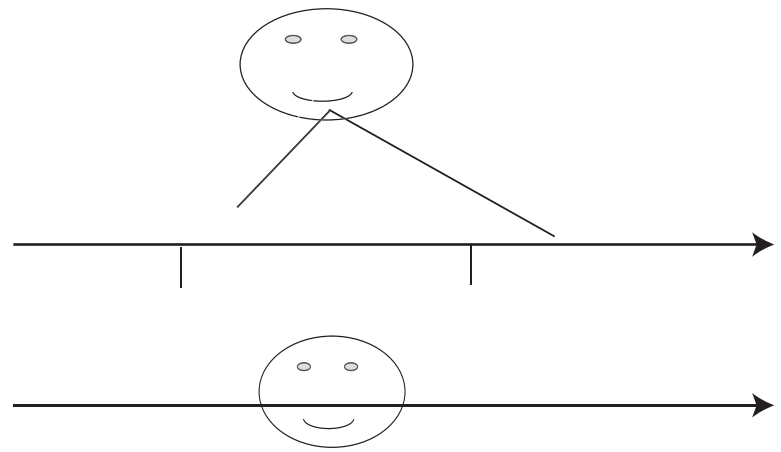

Fig. 2

The interdependence between this kind of perspective and time comes out very neatly in Russian, where the present perfect can never refer to present time; instead it has been harnessed to express future time. (The future imperfect requires an auxiliary, a form of the verb $b e$.) This seems very logical, since it is difficult to embrace a present situation from beginning to end. One might wonder why the English progressive, which is in many ways comparable to the Russian imperfect, does not follow the same pattern. The best explanation I can think of is that the English progressive is the marked term of the system, whereas the Russian imperfect is the unmarked one. Hence it is natural in English to use the unmarked non-progressive in cases (like I think, I know) where the finished perspective is irrelevant, instead of giving it a specific future meaning. But there are no doubt other contributory factors in the development of the two systems.

I shall not strain my meagre pictorial skills to try to draw the interdependence between time and what I have called the retrospective perspective. But it seems possible to envisage retrospective perspective in the form of an eye (above or on the time line) looking back on some event that is in some way relevant to the present. (For the past, future and infinitive perfective the sequential view is sufficient, though it is not difficult to see the 'pre-times' as a kind of retrospection.)

\section{THE WHOLE SYSTEM?}

The question now arises whether it is possible to see behind the various ramifications I have been sketching, a more general temporal system, a skeleton, as it were, on which the various languages depend for the muscle that expresses their particular conceptualisation of time. I can't answer that question, which would require a far wider typological horizon. Instead I shall try to schematise the English system in a way that tries to reduce the complexity to a viable overview - only for presentational purposes though: the actual possibilities in the system go beyond what can be tabularized.

In the table in the appendix I try to illustrate the interdependence between (sequential) time, (temporal) perspective and modality. The table needs a few comments:

- The basis for the table is form and sequential time content. If one were to take aspect or modality as the basis, the table would look quite different. Examples are not given when I consider them to be obvious. 
- The simplest forms ( $1 \& 2$ in the table) seem to have the largest number of interpretations, which is presumably because they are both marked (whereas the others have a marked and an unmarked term), or the most clearly grammaticalized (in that they force a choice on the speaker). Those systems (like $9 \& 10$ : the so-called semi-aux.) which can still be understood in the sense the lexical items dictate, are the least clearly grammaticalized.

- The bold-type temporal sequences of 1-6 show the system which - inspired by Latin - is often taken to be classic: three times/tenses with three pretimes/tenses. However, $5 \mathrm{a}$ is the 'odd-man-out', since the formula $\mathrm{RT}<\mathrm{CT}=\mathrm{ST}$ is an anomaly: ST is by default the CT. This means that $\mathrm{RT}<\mathrm{CT}=\mathrm{ST}$ is the same as RT<ST (cf. 2a), and so this form should either disappear or acquire an alternative meaning (in English the retrospective perspective). Moreover, a 'logical' system would naturally also include 'post-times', such as the 'post-present' and 'post-past' of $9 \& 10 \mathrm{a}$ (cf. also $7 \mathrm{~b} \& 8 \mathrm{~b}$ ), but those are not distinctly grammaticalized (not even in Latin). I cannot think of a plausible example of a 'post-future' (RT>CT $>\mathrm{ST}$ - an example like We shall be going to eat then (with modal + semi-auxiliary) does not sound easily interpretable - though not impossible).

- I have included more senses under 'temporal perspective' than are usually considered to be aspectual. It seems to me that they can all be seen as temporal and perspectival, but this is a matter of terminology. If there had been space for it, I might have included a further column, indicating 'further perspectivization' or 'special temporal meanings'. What seems to me beyond doubt, is that what is usually kept apart as aspect, is closely related to time (as I have argued above). This is also brought home (to me at least) by the fact that it is possible to indicate ongoing perspective by means of a formula which utilizes the same type of symbols as those of sequential time (cf. $7 \mathrm{a}$ $\& 8 \mathrm{a}$ ). The same holds for 'ongoing up-to-now', cf. $13 \& 14$, which are as retrospective as $5 \mathrm{a}$ ).

- I have indicated modal content only where this seemed a significant part of the (special) meaning of the form in question. (Incidentally, the form seemed in the preceding sentence is a special contextual use of the preterite which parallels the RT<> ST of 1b.) The difference between 1c and 3a is the only instance where it is necessary to include 'factual', and it is only partly accurate: for instance, the present tense for future time is idiomatically used in all temporal sub-clauses, even when the meaning is non-factual (cf. also 5b as opposed to 11).

I should emphasize that the table is not exhaustive. There are more meanings (also temporal ones) that can be expressed in the tense-auxiliary system, especially if we include further combinations, such as By then I shall have been working for three hours only ('RT $\angle \mathrm{CT}>\mathrm{ST}$ ' = 'up-to-future'). I don't see any reason to consider this form less grammaticalized than the forms it is made up of.

\section{TIME IN LANGUAGE}

I have limited myself to verbal (morphological and auxiliary) expressions of time. The most salient point that follows from my presentation, is that there is no one-toone correspondence between expression and content. The implications of a particular expression varies with context. There can hardly be any doubt that this principle holds for lexical or lexico-grammatical expressions of time as well (for instance, now and then only rarely means 'in the present and in the past', and while may indicate contrast as 
Arndt, Time, tense ...

well simultaneity). And the way in which lexical verb types may influence the choice and content of tense and aspect is illustrated very convincingly by Bache (1995).

Secondly, tense, aspect and modality work together to express the various relations between speaker time and referential time, with great variation between languages. Modal auxiliaries are particularly visible in the expression of future time in English, less so in Danish, and the preterite tense is routinely used to refer to present time, usually in hypothetical or irreal contexts. Aspect plays a different role, with Russian perfect future as the most salient illustration, but the significance of the concept of time for an understanding of aspect should be clear, also more generally.

The third point I want to make, is that the ways in which language can refer to time are manifold. As far as time sequence is concerned, it is possible to refer to the present, the past and the future (relative to speaking time), using different expressions in different languages, with tense as only one option among several (auxiliaries and particles being two others). Verging on the expression of perspective, we have the 'pre-tenses', which, not surprisingly, are often used to convey speaker's perspective (or what is generally referred to as aspect), such as the perspective of retrospection (relevance to the present time), or duration (attention to the temporal limits of the event described).

Not all languages have grammaticalized the same time expressions. Danish has no grammatical progressive/non-progressive aspect, but there are several idiomatic expressions that express the same thing. The existence of 'pre-times' suggests the possiblity of 'post-times', and it turns out that expressions for these are also in evidence, for instance in French (with the auxiliary aller) and in English (going to), or in Danish (skal til at).

\section{CONCLUSION}

It is interesting to speculate (but I should emphasize that it is no more than speculation) that a two-way distinction between looking backwards and looking forwards may have been a natural consequence of a primeval human situation. Two types of language use may have been conducive to the survival of the species: recounting past events in order to disseminate experience, and deciding about how to cooperate in order to meet the needs of tomorrow.

Further development may then have added the ability to speak about the present, which may be conceptualised either as part of experience or as part of decision-making. The former conceptualisation will have led to a conflation of past and present (tense/ time), with the future as the marked term; the latter will have resulted in a conflation of present and future, with a marked past that is clearly backwards-looking: a tense of stories.

The very tentative evidence that can be adduced for this, is that in the forwards-looking type of conceptualisation, where the future is marked in contrast to the past-present, it might be seen as natural that various kinds of modality would develop (as seems to be the case in the Amazonian, Inuit and Aleut languages I have referred to). Whereas in the backwards-looking type (as in the Indo-European languages) the more natural 
Arndt, Time, tense ...

development could have been that of expressions for various types of aspect/perspective (durative, retrospective, resultative) on the activity one is or was involved in. Looking forwards, one is perhaps less likely to think of what one will be doing, than of what one will do. Looking backwards, one might be less likely to think of epistemic possibility or deontic desirability than of sequences and perspectives.

Of course neither of these two choices excludes the possibility of conceptualizing, or even grammaticalizing, other time relations. And as I said, this is only speculation. There is no logical necessity in the developments I have sketched, nor, indeed, in the outline of time/tense I have presented.

\section{REFERENCES}

Bache, Carl (1995), The Study of Aspect, Tense and Action, Frankfurt/M.: Peter Lang. Bergsland, Knut (1997), Aleut Grammar, Fairbanks, Alaska Native Research Center, University of Alaska Fairbanks.

Chomsky, Noam (1957), Syntactic Structures, The Hague: Mouton.

Kakumasu, James (1986), "Urubu-Kaapor", in: Derbyshire, Desmond C., Geoffrey K. Pullum (eds.) (1986), Handbook of Amazonian Languages, Vol. 1, Berlin: Mouton de Gruyter, pp. 326-403. 
Arndt, Time, tense ...

APPENDIX

Tense and auxiliary forms and meanings in English

\begin{tabular}{|c|c|c|c|c|c|}
\hline & FORM & $\begin{array}{l}\text { TEMPORAL } \\
\text { SEQUENCE }\end{array}$ & $\begin{array}{c}\text { TEMPORAL } \\
\text { PERSPECTIVE }\end{array}$ & MODALITY & EXAMPLES \\
\hline \multicolumn{6}{|c|}{ Simple forms } \\
\hline 1 & present tense & $\begin{array}{l}\text { a. } \mathrm{RT}=\mathrm{ST} \\
\text { b. } \mathrm{RT}<>\mathrm{ST} \\
\text { c. } \mathrm{RT}>\mathrm{ST} \\
\text { d. } \mathrm{RT}<\mathrm{ST}\end{array}$ & $\begin{array}{l}\text { all-time } \\
\text { future-as- } \\
\text { now } \\
\text { vivid past }\end{array}$ & factual & $\begin{array}{l}\text { The moon is round. } \\
\text { I know. } \\
\text { Tomorrow is Tuesday. }\end{array}$ \\
\hline 2 & preterite & $\begin{array}{l}\text { a. } R T<S T \\
\text { b. } R T=S T \\
\text { c. } R T>S T\end{array}$ & & $\begin{array}{l}\text { non-fact. } \\
\text { non-fact. }\end{array}$ & $\begin{array}{l}\text { If you were here ... } \\
\text { If I won (I probably } \\
\text { won't) }\end{array}$ \\
\hline \multicolumn{6}{|c|}{ Forms with one auxiliary } \\
\hline 3 & present+modal & $\begin{array}{l}\text { a. } \mathbf{R T}>\mathrm{ST} \\
\text { b. } \mathrm{RT}=\mathrm{ST}\end{array}$ & & $\begin{array}{l}\text { non-fact. } \\
\text { non-fact. }\end{array}$ & $\begin{array}{l}\text { This won't last. } \\
\text { He may be here } \\
\text { already. }\end{array}$ \\
\hline 4 & $\begin{array}{l}\text { preterite+ } \\
\text { modal }\end{array}$ & $\begin{array}{l}\text { a. } \mathrm{RT}>\mathrm{CT}<\mathrm{ST} \\
\text { b. } \mathrm{RT}=\mathrm{ST} \\
\text { c. } \mathrm{RT}>\mathrm{ST}\end{array}$ & & $\begin{array}{l}\text { non-fact. } \\
\text { non-fact. }\end{array}$ & $\begin{array}{l}\text { (He said) he would } \\
\text { come. } \\
\text { He should be here } \\
\text { now. } \\
\text { I wouldn't go (if I } \\
\text { were you). }\end{array}$ \\
\hline 5 & present+have & $\begin{array}{l}\text { a. }(\mathbf{R T}<\mathbf{C T}=\mathbf{S T}) \\
\text { b. } \mathrm{RT}<\mathrm{CT}>\mathrm{ST}\end{array}$ & $\begin{array}{l}\text { retrospective } \\
\text { pre-future }\end{array}$ & & $\begin{array}{l}\text { When we have eaten } \\
\text { (I'll...). }\end{array}$ \\
\hline 6 & preterite+have & $\begin{array}{l}\text { a. } \mathrm{RT}<\mathrm{CT}<\mathrm{ST} \\
\text { b. } \mathrm{RT}<\mathrm{ST}\end{array}$ & pre-past & non-fact. & $\begin{array}{l}\text { When we had slept } \\
\text { (we ate). } \\
\text { If I had known (but I } \\
\text { didn't). }\end{array}$ \\
\hline 7 & present progr. & $\begin{array}{l}\text { a. } \mathbf{R T}<>\text { ST } \\
\text { b. RT }>\text { ST }\end{array}$ & $\begin{array}{l}\text { ongoing } \\
\text { planned fut. }\end{array}$ & & We are eating at six. \\
\hline 8 & preterite progr. & $\begin{array}{l}\text { a. RT }<>\text { CT }<\text { ST } \\
\text { b. } \mathrm{RT}>\mathrm{CT}<\mathrm{ST}\end{array}$ & $\begin{array}{l}\text { ongoing } \\
\text { planned fut. } \\
\text { in the past }\end{array}$ & & $\begin{array}{l}\text { (You said) we were } \\
\text { eating at six. }\end{array}$ \\
\hline \multicolumn{6}{|c|}{ Forms with semi-aux } \\
\hline 9 & pres.+going to & a. $\mathbf{R T}>\mathbf{S T}$ & planned fut. & & \\
\hline 10 & pret.+going to & $\begin{array}{l}\text { a. } \mathrm{RT}>\mathrm{CT}<\mathrm{ST} \\
\text { b. RT }>\text { ST }\end{array}$ & $\begin{array}{l}\text { planned fut. } \\
\text { in the past } \\
\text { planned fut. }\end{array}$ & non-fact. & $\begin{array}{l}\text { (He came just as) we } \\
\text { were going to leave. } \\
\text { We were going to } \\
\text { eat now (but we had } \\
\text { better wait). }\end{array}$ \\
\hline
\end{tabular}

(continues...) 
Arndt, Time, tense ...

(... continued)

\begin{tabular}{|c|c|c|c|c|c|}
\hline & FORM & $\begin{array}{l}\text { TEMPORAL } \\
\text { SEQUENCE }\end{array}$ & $\begin{array}{c}\text { TEMPORAL } \\
\text { PERSPECTIVE }\end{array}$ & MODALITY & EXAMPLES \\
\hline \multicolumn{6}{|c|}{ Forms with two auxiliaries } \\
\hline 11 & $\begin{array}{l}\text { pres. }+ \text { modal+ } \\
\text { have }\end{array}$ & a. $\mathbf{R T}<\mathrm{CT}>\mathbf{S T}$ & pre-future & & $\begin{array}{l}\text { We'll have eaten by } \\
\text { then. }\end{array}$ \\
\hline 12 & $\begin{array}{l}\text { pret.+modal+ } \\
\text { have }\end{array}$ & $\begin{array}{l}\text { a. } \mathrm{RT}<\mathrm{CT}<\mathrm{ST} \\
\text { b. } \mathrm{RT}<\mathrm{ST}\end{array}$ & & non-fact. & $\begin{array}{l}\text { We would have eaten } \\
\text { by then. } \\
\text { We would have eaten } \\
\text { (but..) }\end{array}$ \\
\hline 13 & $\begin{array}{l}\text { pres.+have+ } \\
\text { progr. }\end{array}$ & a. $\mathrm{RT} \angle S \mathrm{ST}$ & up-to-now & & I have been working. \\
\hline 14 & $\begin{array}{l}\text { pret.+have+ } \\
\text { progr. }\end{array}$ & a. $\mathrm{RT} \leqslant \mathrm{CT}<\mathrm{ST}$ & up-to-then & & I had been working. \\
\hline
\end{tabular}

\section{Abbreviations and symbols}

RT Referential time, i.e. the point in time to which the main predication refers

ST Speaker time, i.e. the deictic to which RT is related

CT Contextual time, i.e. a point in time that may provide a secondary relation for RT

fut. future

non-fact. non-factual or counter-factual

pres. present

pret. preterite

progr. progressive (be+-ing)

$>\quad$ After

$<\quad$ Before

$\leq \quad$ Before and up to XT

$<>\quad$ Includes, e.g. 'RT $<>\mathrm{ST}^{\prime}=$ 'RT is both before and after ST' 